\title{
CORRIGENDUM
}

\section{Electrically tuned spin-orbit interaction in an InAs self-assembled quantum dot}

Y. Kanai, R. S. Deacon, S. Takahashi, A. Oiwa, K. Yoshida, K. Shibata, K. Hirakawa, Y. Tokura and S. Tarucha

Nature Nanotechnology 6, 511-516 (2011); published online 24 July 2011; corrected after print 22 November 2011.

In the version of this Letter originally published, in the discussion of Fig. $5 \mathrm{c}$ on page 514 , the fitting function should have been $\Delta=A\left|\cos \left(\theta-\theta_{0} \pm \pi / 2\right)\right|+B$, and the offsets of $\theta_{0}$ should have been $-30 \pm 4^{\circ}$ and $-39 \pm 5^{\circ}$ for $V_{\mathrm{sg}}=-0.5 \mathrm{~V}$ and $1.0 \mathrm{~V}$, respectively. These errors have been corrected in the HTML and PDF versions of the Letter. 